IZA DP No. 6417

Social Identity and Inequality:

The Impact of China's Hukou System

Farzana Afridi

Sherry Xin Li

Yufei Ren

March 2012 


\title{
Social Identity and Inequality: The Impact of China's Hukou System
}

\author{
Farzana Afridi \\ Indian Statistical Institute \\ and IZA \\ Sherry Xin Li \\ University of Texas at Dallas \\ Yufei Ren \\ Union College
}

\section{Discussion Paper No. 6417 \\ March 2012}

\author{
IZA \\ P.O. Box 7240 \\ 53072 Bonn \\ Germany \\ Phone: +49-228-3894-0 \\ Fax: +49-228-3894-180 \\ E-mail: iza@iza.org
}

Any opinions expressed here are those of the author(s) and not those of IZA. Research published in this series may include views on policy, but the institute itself takes no institutional policy positions.

The Institute for the Study of Labor (IZA) in Bonn is a local and virtual international research center and a place of communication between science, politics and business. IZA is an independent nonprofit organization supported by Deutsche Post Foundation. The center is associated with the University of Bonn and offers a stimulating research environment through its international network, workshops and conferences, data service, project support, research visits and doctoral program. IZA engages in (i) original and internationally competitive research in all fields of labor economics, (ii) development of policy concepts, and (iii) dissemination of research results and concepts to the interested public.

IZA Discussion Papers often represent preliminary work and are circulated to encourage discussion. Citation of such a paper should account for its provisional character. A revised version may be available directly from the author. 
IZA Discussion Paper No. 6417

March 2012

\section{ABSTRACT \\ Social Identity and Inequality: The Impact of China's Hukou System}

We conduct an experimental study to investigate the causal impact of social identity on individuals' response to economic incentives. We focus on China's household registration (hukou) system which favors urban residents and discriminates against rural residents in resource allocation. Our results indicate that making individuals' hukou status salient and public significantly reduces the performance of rural migrant students on an incentivized cognitive task by 10 percent, which leads to a significant leftward shift of their earnings distribution. The results demonstrate the impact of institutionally imposed social identity on individuals' intrinsic response to incentives, and consequently on widening income inequality.

JEL Classification: $\quad$ C93, D03, O15, P36

Keywords: $\quad$ social identity, inequality, field experiment, hukou, China

Corresponding author:

Sherry Xin Li

EPPS

The University of Texas at Dallas

800 W. Campbell Road, M/S GR31

Richardson, TX 75080-3021

USA

E-mail: sherry.xin.li@utdallas.edu 


\section{Introduction}

A large body of literature documents significant and increasing income inequality in the fastest growing economies of the world (in China: Kanbur and Zhang, 1999; Chen, 2002; Yao, Zhang and Hanmer, 2004; Ravallion and Chen, 2007; in India: Deaton and Dreze, 2002; Datt and Ravallion, 2002). Empirical research suggests that rising income inequality lowers poverty reduction at any given positive rate of growth (Ravallion, 1997). If we incorporate the psychology and sociology of an individual's identity into economic models of behavior, however, the implications of socio-economic inequality may be much wider. For instance, Akerlof and Kranton (2000) incorporate individuals' social identity into a theoretical model of poverty and show that social exclusion can lead to equilibria in which the 'excluded' individuals avoid economic activities that are remunerative.

This paper extends the literature on social identity by investigating how individuals' identification with an institutionally created underclass contributes to economic inequality. We focus on China's household registration system - the hukou institution. This system categorizes citizens into urban (nonagricultural) and rural (agricultural) residents of a particular location. The urban residents in that location (say a municipality) are favored in resource allocation compared to the rural residents and migrants. We design a framed field experiment (Harrison and List, 2004) to study whether this institution shapes an individual's social identity and has a causal impact on her response to incentives. If yes, how does the response to incentives affect individuals' performance on cognitive tasks and thereby the distribution of earnings among these different socio-economic groups?

To introduce an exogenous variation in identity salience we adopt a methodology from

psychology called priming (Bargh, 2006). Specifically, we randomly assign primary school students in Beijing, with different hukou backgrounds, to two treatments. In the identity 
treatment we prime students' hukou identity and make it salient through a pre-experiment questionnaire followed by a public verification of their hukou status (Shih, Pittinsky and Ambady, 1999; Hoff and Pandey, 2006). In the control treatment students' hukou identity is kept private. We then compare the performance in incentivized cognitive tasks, solving puzzles, between the two treatments in order to examine the effects of hukou identity on economic inequality.

Our experimental design follows Hoff and Pandey $(2005,2006)$ who were the first to explore how social identities contribute to income inequality through intrinsically distorted response to incentives in India. This paper extends their investigation to China - the world's most populous country and fastest growing economy - and more importantly, to a broader horizon in several ways. First, we explore the impact of identity within a socio-political system that is almost polar opposite of India's. Unlike India, China is an ethnically homogeneous society - its population is 91.5 percent ethnic Han (National Bureau of Statistics 1994-2003). While the caste system is based on factors that include race, ethnicity, linguistics, and occupations, the rural-versus-urban categorization by China's hukou system is less complex. The relatively simple social categorization by hukou, therefore, provides cleaner evidence on how powerful institutional exclusion can be, even in an ethnically homogeneous society, in influencing labor market outcomes through individuals' social identities. Second, unlike caste or ethnicity, migrant identity in China is administratively created to control spatial labor mobility and reinforced through merely decades of differential treatment of rural-urban residents. We, therefore, have an opportunity to test whether systemic disparity between households over a short period of time (compared to hundreds of years for caste and ethnic disparities) can be internalized through a manifestation of individuals' social identity. If yes, this provides us with more powerful evidence on the impact of institutions and social exclusion in creating identities. Finally, as a policy 
intervention in the domestic labor market, China's hukou system was initially designed to prevent potential problems that may be caused by massive rural-urban labor migration. By focusing on migrant identity created by such a policy as well as the resulting consequences, this paper carries broader implications for policy making in other economies where regional labor migration or global immigration may pose challenges in the labor markets.

Our results indicate that when rural migrant students' 'inferior' hukou status is made salient and public, they significantly underperform by 10 percent in the incentivized cognitive task compared to when their identity is kept private. The performance of local urban students, the 'high' status hukou holders, insignificantly improves when their hukou status is primed. Consistent with Hoff and Pandey (2011), we find that introducing competition significantly enhances the performance of 'high' status males but publicly revealing the 'inferior' status of their competitors makes them complacent.

Although these changes in behavior have insignificant impact on aggregate efficiency, the significant underperformance by rural migrant students leads to a drastic shift in the experimental earnings distribution. The ranking of rural migrant students shifts to the left - the proportion of rural migrant students below the $25^{\text {th }}$ percentile increases significantly from 11.9 percent to 30.3 percent. In contrast, when hukou identity is primed the proportion of urban students below the $25^{\text {th }}$ percentile drops from 22.2 percent to 17.2 percent, and the proportion above the $75^{\text {th }}$ percentile increases by almost 8 percentage points, albeit insignificantly. The results show that the hukou system distorts individuals' response to incentives and may have a causal impact on widening the income gap between migrants and non-migrants in urban China. They suggest that a policy intervention based on categorizations of citizens and differential treatments may be internalized by individuals, and hence lead to unintended, far-reaching 
economic consequences.

Our findings have two broad implications. First, theoretical and empirical literature suggests that high levels of inequality may have adverse implications for economic growth (Persson and Tabellini, 1994; Alessina and Rodrik, 1994). Our results, thus, highlight the importance of designing policies that ensure inclusive and sustainable economic growth in developing countries. Second, the results underline the need for more research on the impact of social exclusion on individual behavior and the effectiveness of existing redistributive policies that aim at reducing social exclusion. For instance, while affirmative action has generated tremendous policy debate, there is limited evidence of its impact on social cohesion as well as economic efficiency.

The remaining sections of the paper are organized as follows. Section 2 places this study in the context of existing literature. Section 3 provides a brief background on China's hukou system. Section 4 describes the experimental design and the data. The results of the analysis and its discussion are presented in Section 5. Section 6 concludes.

\section{Literature Review}

The importance of incorporating social identity into economic analyses is stressed by Akerlof and Kranton (2000). An expanding theoretical (Shayo, 2005; Fang and Loury, 2005; Benabou and Tirole, 2007; Horst, Kirman and Teschl, 2006) and a growing number of experimental economics studies show that social identity has important impact on preferences and economic behavior (Eckel and Grossman 2005; Goette, Huffman and Meier 2006; Charness, Rigotti and Rustichini 2007; Chen and Li 2009; Benjamin, Choi and Strickland, 2010; Benjamin, Choi and Fisher, 2010; Chen and Chen forthcoming; Charness, Cobo-Reyes and Jiménez 2011). To the 
best of our knowledge, only two studies investigate the impact of social identity on economic outcomes in developing countries. Hoff and Pandey $(2005,2006)$ find that social identity - a product of history and culture - shapes one's belief system and has a pronounced impact on behavior in response to economic incentives through self-confidence and trust. They show that making caste salient to middle school male students in rural India lowers the performance of low-castes relative to high-castes even when rewards for performance depend solely on individual effort. Hoff and Stiglitz (2010) discuss why ideologies of social unworthiness, as cognitive frames, can be so powerful.

Concerns about rising inequality accompanying rapid economic growth have been growing in recent years. In China, income inequality has risen significantly since economic reforms were initiated in 1978 (Ravallion and Chen, 2007; Yao, Zhang and Hanmer, 2004; Chen, 2002; Kanbur and Zhang, 1999). Seventy percent of the overall income inequality in China was accounted by rural-urban inequality during 1983-1995. Further, the contribution of intra-urban inequality to overall inequality increased by 96 percent over the same period (Kanbur and Zhang, 1999). Behind these inequality statistics lie rapid urbanization (Ravallion and Chen, 2007) and the accompanying labor migration from rural to urban areas - the largest in world history. Because of the hukou institution, migrant workers, most being unskilled rural laborers, are treated as ‘outsiders' with limited access to economic resources and opportunities (Liu, 2005).

Research suggests that on average those with a rural hukou are socio-economically worseoff than those with an urban hukou in China. ${ }^{1}$ However, due to confounding unobservable individual characteristics, causality between hukou status, self perceptions and economic

\footnotetext{
${ }^{1}$ Liu (2005) finds that compared to urban residents those who obtained urban hukou later in their lives have significantly lower educational attainment and healthcare benefits. Lu and Song (2006) find that local urban workers earn substantially higher hourly wage than those without local urban hukou. Whalley and Zhang (2007) show that removing hukou barriers to domestic labor mobility will significantly reduce inequality and increase economic efficiency gains.
} 
behavior is hard to establish using survey data or direct field observations. Hence, the current literature almost entirely focuses on restricted labor mobility and discrimination in resource allocation in the hukou system to explain rural-urban and intra-urban economic inequality (Liu, 2005; Lu and Song, 2006; Whalley and Zhang, 2007). Moreover, since official survey data collected by local governments are only inclusive of registered migrant workers, intra-urban income inequality tends to be underestimated (Ravallion and Chen, 2007).

\section{The Hukou System and Social Identity in China}

The household registration or hukou system evolved gradually following the success of the communist revolution in China in 1949. Under this system every citizen was legally bound to register her or his single permanent place of residence (hukou suozaidi) say city $x$ in province $y$, and the type of hukou (hukou leibie) which was either agricultural (rural) or non-agricultural (urban). Strict controls were imposed on mobility of rural hukou holders to urban areas, perpetuating discrimination against them in several ways. Urban employment was primarily determined by workers' hukou status which favored urban residents (Chan and Zhang, 1999). Urban hukou holders, but not rural hukou holders, were eligible for the ration stamps that guaranteed subsidized products (Liu, 2005). Urban residents (particularly employees of the stateowned enterprises) were granted generous fringe benefits including subsidized housing, health services and education. In contrast, such benefits to rural residents were provided by their

communes or villages, which were usually of inferior quality and of highly varying reliability (Lin, Cai and Li 1996; Cheng and Selden, 1994). A household's hukou was (and continues to be) inherited by the next generation. Hukou status and thereby educational attainment and eventually 
employment opportunities of the next generation of rural populace was restricted by birth. ${ }^{2}$

Following China's transition from a centralized to a market economy starting in the late 1970s, the number of people migrating in search of jobs surged following market reforms (and abolition of communes) and an easing of government regulations on spatial migration. The past three decades have, thus, witnessed a drastic increase in the number of 'temporary' non-hukou residents (either registered or non-registered) in urban centers. However, these migrants are not entitled to urban benefits unless their hukou is converted to a full urban one. Rural-urban hukou conversion is possible but only through very limited channels. ${ }^{3}$ Thus the hukou system transitioned from an institution of direct to indirect control over spatial migration.

As of when this study was conducted, the following major and persistent gaps between rural migrants and urban residents existed in large urban centers: (1) labor market and occupational segregation: employment in government offices and state-owned enterprises in cities continued to be unavailable to rural migrant workers unless they converted to an urban hukou; (2) lack of social insurance and social welfare benefits for rural migrant workers such as unemployment and health benefits. In addition, government subsidized low-rent housing in large cities is only available for local urban hukou holders.

It is important to realize that these factors, along with the resulting social segregation of migrants, suggest that the experience of a rural migrant in China is not transitory like in other developing countries (Chan, 1996; Solinger, 1999). Geographical control of rural populace until the 1970s has been replaced by economic and social divisions between rural and urban hukou holders within urban areas of China.

\footnotetext{
${ }^{2}$ Before 1998, children of rural-urban marriages had to follow the mothers' hukou status (Chan and Zhang, 1999). They are now allowed to inherit either the fathers' or the mothers' hukou.

${ }^{3}$ Possible channels for rural-urban hukou conversion include recruitment by state-owned enterprises, enrollment in higher education institutions, and land acquisition by government (Chan and Zhang, 1999). Since 1992 urban hukous are also sold for high fees to eligible investors, property buyers and professionals.
} 


\section{The Hukou System and Schooling in Urban China}

Chinese citizens are entitled to subsidized public education only in the area of their legal permanent residency. In most cities non-local hukou holders cannot enroll their children in local schools unless the schools have quotas for 'guest' students. These 'guests' usually have to pay higher fees than local hukou holders, and the fees can be a significant proportion of migrants' incomes (Xinhua News Agency, July 10, 2002). ${ }^{4}$ Slum schools built by migrant workers exclusively for their children are typically opposed by local authorities, or stringent physical and financial requirements are imposed on them to obtain a legal status.

Due to the hukou classification system, urban areas contain both non-agricultural and agricultural hukou population (Chan and Zhang, 1999). Thus the population in large municipalities such as Beijing and Shanghai usually consist of four different hukou categories: local urban (residents of the urban areas of municipality), non-local urban (migrants who are urban residents of less-developed cities), local rural (residents of the rural areas of municipality), and non-local rural hukou holders (migrants from rural areas of provinces outside municipality). The local urban residents are considered to be at the top of the social hierarchy while the migrants from rural areas are typically at the bottom. But the comparison of socio-economic status between local rural and non-local urban is not clear. Due to this ambiguity and the constraints we faced in subject recruiting, we excluded the local rural and non-local urban hukou holders from this study, and focused on the two sharply disparate groups. Since our experiment

\footnotetext{
4 According to the report, “..... These (migrant) schools teach between 20 and 3,000 students each and charge about $¥ 300$ (US\$36.1) each term. When migrant children go to public schools, their parents have to pay $¥ 500$ (60.2 US dollars) in tuition fees each term, plus $¥ 1,000$ (120.5 US dollars) for selection of the school and $¥ 1,000$ to $¥ 30,000$ (3614.5 US dollars) as sponsorship.”(http://www.10thnpc.org.cn/english/China/36594.htm). Migrant laborers in Chinese cities earn an average of $¥ 966$ per month in 2006 according to a National Bureau of Statistics Survey Report. (http://english.peopledaily.com.cn/200610/22/eng20061022_314208.html)
} 
was conducted in Beijing, this study includes Beijing urban (hereafter $\underline{\text { High) }}$ and non-Beijing rural (hereafter Low) hukou holders.

\section{Experimental Design}

Our experiment adopts the design of Hoff and Pandey (2006). We manipulate hukou salience subjects' hukou status is made salient and public in the identity treatment, and is kept private in the control treatment. We also vary the payment regime by using piece rate and tournament games in each of the treatments.

Selection of subjects Participants in our experiment were 8-12 year old students recruited at four elementary public schools in Beijing. These schools suited the requirements of our experiment on several fronts. The schools admitted non-Beijing hukou students. The proportion of students from migrant families was comparable to the migrant population of the Beijing metropolitan area, and these schools were located in districts where per capita GDP was comparable to the average in the Beijing municipal area. We obtained individual hukou records in advance from the schools' registrar's office for assigning subjects to experimental sessions.

The study focuses on primary school students rather than adults for several reasons. First, focusing on young individuals allows us to avoid using selective samples of people whose decision to migrate to cities may be systematically correlated with their abilities and intrinsic preferences. Second, using adult subjects may introduce potential confounds since their accent and clothing usually provides clues to where they originate from and give away their hukou status even in the absence of the hukou identity prime. Since our subjects wore identical school uniforms and, relative to adults, the young tend to pick up local accents easily, the choice of subject pool ensured that it was difficult to observationally infer one's hukou type. Finally, a study that identifies potential adverse impact of the hukou system on young migrants would 
suggest the importance of policy interventions starting at young ages. Although our sample was young, almost all participants understood what their hukou status was.

We recruited subjects from among 3-6 graders at three schools and among 3-5 graders in one. Each session of the experiment consisted of six subjects of the same gender with three from each of the $\mathrm{H}$ and $\mathrm{L}$ hukou types. To minimize the probability that students knew one another $a$ priori, we obtained student rosters and stratified children by gender, grade, grade section, and hukou type. Three students of the same hukou type were randomly selected, each from a different grade. Two students from the same grade (with different hukou types) were randomly selected, each from a different class section. The sessions in both treatments were formed in the same way. Identity manipulation The identity treatment differs from the control by manipulating the salience of one's hukou identity before the incentivized tasks. Priming, a technique often used in psychology, introduces certain stimuli (including image, audio, or text such as a questionnaire and an article) to activate subjects' knowledge of social structures. As shown in a large literature in psychology (see Bargh, 2006 for a review) and a few recent economic studies (Hoff and Pandey, 2006; Benjamin, Choi and Strickland, 2010; Benjamin, Choi and Fisher, 2010), priming social identities may influence behavior and attitudes.

In this study, we made hukou identity salient in the identity treatment by using a survey and publicly verifying subjects' hukou status at the beginning of the experiment, while in the control treatment subjects' hukou identity was kept private and not primed. In the pre-experiment survey used to prime hukou identity, subjects were asked where they were born, whether they spoke Beijing dialect at home, whether they (or their classmates or teachers) considered themselves as a Beijing local, and how much miscellaneous fees they were charged by the school at the beginning of the semester. They were also asked to compare Beijing local students with 'guest' 
students on academic performance, class participation, extracurricular activities and achievement, and daily spending. After the survey, individuals' hukou was publicly verified by the experimenter along with other factual information in the following order: name, date and month of birth, and hukou. ${ }^{5}$ This procedure simulated some real life scenarios these students experience in school. For example, to determine the amount of miscellaneous fees due, students' hukou status needs to be verified, sometimes in public. ${ }^{6}$ Although rural migrants do not have equal access to socio-economic resources as local urban residents, a rural hukou status is usually not perceived as a matter of shame in Chinese society. In the control treatment, the sessions started with neither the survey nor public verification of hukou and proceeded directly to the incentivized cognitive task.

Incentivized cognitive task The experiment was conducted using paper and pencil in a standard classroom setting with six subjects (3 H and 3 L types) seated at separate desks with fairly large distance from one another. Randomly assigned subject ID numbers were used to ensure anonymity of decisions throughout the experiment. Before the experiment started participants were greeted by a female experimenter and each paid 3 Chinese yuan (¥3) participation fee upon arrival. The experimenter then explained the tasks and rules. We used level-2 maze puzzles from Yahoo! games (Gneezy, Niederle, and Rustichini, 2003; Niederle and Vesterlund, 2007; Hoff and Pandey, 2006). The task was to find a path through the field from one side to the other without crossing the solid lines (Appendix A). The experimenter explained the rules using a simple maze, and showed how to solve another one of similar difficulty level as those used in the experiment. Subjects were given five minutes to practice with an additional

\footnotetext{
${ }^{5}$ The experimenter said in public, "According to the information from the school's registrar's office, your hukou belongs to [province/city] and it is a(n) [agricultural/non-agricultural] hukou." Student's year of birth was not revealed to avoid affecting their self-confidence given that they were from three different grades.

${ }^{6}$ Unlike in many western countries, date of birth, students' grades and, similarly hukou status, are not treated as confidential information in Chinese culture.
} 
maze, then participated in two 15-minute blocks of experiment. In each block, they were given a booklet of 15 mazes, and had up to 15 minutes to solve as many as possible. All the thirty mazes were of identical difficulty level.

The homogeneous reward system (hereafter the Pure Piece Rate regime) used piece rate compensation in both blocks - subjects were rewarded with $¥ 1$ for each maze solved correctly. The heterogeneous reward system (hereafter the Mixed Tournament regime) consists of piece rate in the first block (¥1 per maze), and tournament in the second block in which only the winner (who solved the most number of mazes in the session) was rewarded with $¥ 6$ per maze and other subjects received zero. ${ }^{7}$ In the case of a tie, each of those who solved the highest number of mazes was rewarded with $¥ 6$ per maze.

Subjects were told that the task consisted of two blocks. But the instruction for the second block, including the payment scheme, was not given until after block one. Therefore, the payment structure is identical in block one for the Pure Piece Rate regime and the Mixed Tournament regime. At the end of each block maze booklets were collected and left outside the 'labs' to be picked up by a research assistant and handed to the graders in a separate room. The procedure prevented the graders from knowing the subjects' identities and hukou status. Since the experimenters never left the labs at any point of time during the session, subjects were aware that their mazes were not graded by their experimenters. A survey was conducted at the end to collect demographic information. Thereafter, the grading results were handed to the experimenters, subjects were then informed about their performance (and results of the tournament, if applicable), paid individually in private, and dismissed.

The experiment was conducted in May and December 2007, and December 2008. At each school the experiment included four conditions including the Pure Piece Rate control treatment,

\footnotetext{
${ }^{7}$ To avoid zero payoffs we did not use tournament in both blocks.
} 
Pure Piece Rate identity treatment, Mixed Tournament control treatment, and Mixed Tournament identity treatment. Table 1 summarizes the features of experimental sessions. Experimental sessions were conducted separately for boys and girls during class breaks on school days. In total we conducted 72 sessions, including 48 male sessions and 24 female sessions with mixed hukou types. The total number of subjects was $418 .{ }^{8}$ Average earnings per subject were $¥ 19.70$ in the control treatment and $¥ 19.60$ in the identity treatment, about three times the average weekly allowance that these students received from their parents.

The summary statistics presented in Table 2 show no statistically significant difference in the demographics and other related variables between the identity and control treatments, indicating successful randomization of students across experimental treatments. The average number of other students that a subject had prior acquaintance with was 1.4 per session, comparable to Hoff and Pandey (2006). Among the L hukou students, 22 percent were born in Beijing. The remaining L subjects had lived in Beijing for 5.5 years on average, or more than 50 percent of their current life time. Although the L subjects spoke in a perfect local accent and dressed in a way that was indistinguishable from their local counterparts, their self-image was highly correlated with their hukou status. According to the survey data, only 9 percent of L subjects (compared to 85 percent of $\mathrm{H}$ subjects, $p<0.01$ ) considered themselves Beijing locals and only 33 percent of L subjects compared to 89 percent of $\mathrm{H}$ subjects $(p<0.01)$ expected to be considered a Beijing local by their fellow students or teachers.

\section{Results}

In this section, the two blocks in the Pure Piece Rate regime and the first block in the Mixed Tournament regime are referred to as the piece rate blocks since they all involve the piece rate

\footnotetext{
${ }^{8}$ The instructions are adopted from Hoff and Pandey (2006). The English translation of the experimental instruction
} and surveys are included in Appendices B - D. 
payment method. The second block in the Mixed Tournament regime is referred to as the tournament block. Data in the first blocks of both payment regimes are pooled whenever appropriate because of the identical experimental design. We present descriptive statistics then discuss the regression analyses which incorporate individual and school characteristics. Two tail test $p$ values are reported unless noted otherwise.

Figure 1 shows the average number of mazes solved by gender and hukou in the first blocks of both regimes (panel A), block 2 of the Pure Piece Rate regime (panel B) and block 2 of the Mixed Tournament regime (panel C). As shown in the control treatment in panel A, conditional on gender, $\mathrm{H}$ and $\mathrm{L}$ hukou groups exhibit little difference in their intrinsic maze solving ability. Their performance diverges in the treatment, however, in response to the hukou identity priming. Panels A and B suggest that when hukou was publically revealed in a noncompetitive environment, the number of mazes solved by $\mathrm{H}$ boys and girls increased $(p>0.10)$ while it decreased for L boys and girls $(p<0.05, \mathrm{t}$ test of means by pooling data for piece rate blocks for both genders and controlling for round fixed effect). Panel $\mathrm{C}$ suggests that in a competitive environment, both $\mathrm{H}$ and L boys' performance declined, and both $\mathrm{H}$ and $\mathrm{L}$ girls performed better in the identity treatment than in the control $(p>0.10)$.

Figures 2 and 3 summarize the experimental earnings in the Pure Piece Rate regime, with Figure 2 contrasting average earnings across the two treatments and Figure 3 disaggregating the results by quintiles of earnings distribution. ${ }^{9}$ Figure 2 shows no significant difference in earnings between the $\mathrm{L}$ and $\mathrm{H}$ subjects $(p>0.10)$ for each gender group in the control treatment. When hukou is primed the L types earn significantly less than the H types (boys: 14.1 vs. 16.5, $p<0.05$; girls: 11.9 vs. 13.9, $p>0.10$ ). Confirming the results in Figure 2, Figure 3 shows a rightward

\footnotetext{
${ }^{9}$ The $¥ 3$ participation fee was not included. Earnings under the Mixed Tournament regime are not the focus here due to the large variance because of the winner-take-all rule.
} 
shift of the earnings distribution for $\mathrm{H}$ subjects and a leftward shift for L subjects $(p<0.10$ in both cases, two-side rank sum test) as a result of hukou priming. ${ }^{10}$

We next use the following school-fixed-effect model to analyze the determinants of individual performance and distribution of experimental earnings.

$Y_{i s}=\beta_{0}+\beta_{1}$ salient hukou $_{i}+\beta_{2} L_{i}+\beta_{3}\left(L_{i} \cdot\right.$ salient hukou $\left._{i}\right)+\beta_{4}$ female $_{i}+\beta_{5}$ grade $_{i}+\beta_{6}$ block $_{i}+\alpha_{s}+$ $\eta_{\text {is }}$

We pool data of $\mathrm{H}$ and $\mathrm{L}$ subjects, boys and girls, to compare the impact of hukou priming across hukou status and gender. Two dependent variables of interest $\left(Y_{i s}\right)$ include the number of mazes solved by, and (experimental) earnings percentile of individual $i$ in school $s$. The independent variables include dummy variables for the identity treatment (salient hukou), low hukou type $(L)$ ( $\mathrm{H}$ type in the omitted category), and gender (female). The treatment variable Salient hukou is interacted with $L$ to allow its impact to differ with hukou type. We control for grade, and block 2 when applicable. ${ }^{11}$ School fixed effects, $\alpha_{s}$, control for unobservable, school-specific characteristics. $\eta_{i s}$ is the error term. Standard errors are clustered at the individual level wherever appropriate. The results are presented in Table 3 .

The first two columns of Table 3 present results for the number of mazes solved. Column 1 pools data from both blocks of the Pure Piece Rate regime and block 1 of the Mixed Tournament regime, hence a dummy variable block 2 is used to control for improvement in performance. Results show that in the piece rate blocks, hukou priming insignificantly increases H group's performance (coefficient $0.300, p>0.10$ ), but significantly decreases L group's performance since the coefficients of salient hukou and its interaction with $L$ suggest that $\mathrm{L}$ subjects solved

\footnotetext{
${ }^{10}$ Figure 3 pools data of females and males for each hukou type. The pattern is similar if the distributions are separated by gender. Figure A1 in the appendix presents the distribution of actual experimental earnings, rather than earnings percentiles, and shows similar results.

${ }^{11}$ The correlation between grade and subjects' age is $0.7(p<0.01)$. Results are consistent using age or grade. Including or excluding other control variables (the number of subjects in the session, prior experience with the mazes, and family background) does not change the findings.
} 
$0.772(p<0.01)$ less mazes in the identity treatment than in the control. ${ }^{12}$ This impact on $\mathrm{L}$ subjects is both statistically significant and economically substantial. Given that the L group solved 7.6 mazes on average in the Pure Piece Rate regime in the control treatment, this effect represents a 10 percent drop in performance by the L group. In the tournament block (column 2), the hukou identity has insignificant impact on competitiveness for the $\mathrm{H}$ and $\mathrm{L}$ groups $(p>0.10)$. In both columns 1-2, the effects of other covariates are consistent with our expectations. Boys solved more mazes than girls. The higher the grade, the better is the individual's performance. The large positive coefficient of block 2 in column 1 suggests substantial improvement in performance over time. The above analysis leads to our first result.

Result 1 (Performance in piece rate blocks). In the piece rate blocks the hukou priming significantly reduces the performance of the $\mathrm{L}$ subjects, and insignificantly increases the performance of the $\mathrm{H}$ subjects.

Result 1 implies that one's hukou identity, when publicly revealed, may distort individual's response to incentive. What does this distortion entail regarding the income distribution across different hukou groups? Presume that the control treatment simulates the 'state' without systemic discrimination whereas the treatment condition simulates the 'state' with discrimination. If we then rank subjects (regardless of gender and hukou background) based on their experimental earnings in the control and the identity treatment, respectively, any difference in the distribution of earnings between the two states can be inferred as evidence of the impact of the hukou system in distorting individuals' response to incentives. Descriptive statistics on earnings percentiles (Figure 3) show that 53 percent of $\mathrm{H}$ subjects and 38 percent of $\mathrm{L}$ subjects rank below the median earning in the control treatment, whereas 41 percent of $\mathrm{H}$ subjects and 58 percent of $\mathrm{L}$

\footnotetext{
${ }^{12}$ The coefficients of salient hukou and its interaction with $L$ are 0.300 and -1.072 , respectively. It suggests that the impact of publicly revealing hukou on L hukou group's effort is $0.772(p<0.01)$.
} 
subjects rank below the median earning in the treatment condition. This suggests that the proportion of $\mathrm{L}$ subjects in the low earnings bracket rises due to their reduced performance $(p<$ 0.05, two-side test of proportion) caused by discrimination in hukou. Column 3 of Table 3 confirms this result. The dependent variable is subject's earnings percentile. The coefficient of salient hukou is $7.458(p>0.10)$, suggesting that priming hukou identity insignificantly increases $\mathrm{H}$ hukou group's ranking in the earnings distribution. The sum of the coefficients of salient hukou and its interaction with $L(-11.74, p<0.05)$ suggests that publicly revealing one's hukou identity significantly decreases a migrant student's ranking in the earnings distribution by 11.74 percentiles. Column 4 reports ordered probit results with four earnings categories (see Figure 3) as the dependent variables. The results are consistent with those in column 3 . We also find that girls generally ranked lower than boys $(p<0.01)$, and students from higher grades ranked higher than those from lower grades $(p<0.01)$. This finding leads to result 2 .

Result 2 (Earnings distribution). Under the Pure Piece Rate regime, priming hukou identity significantly decrease the L type subjects' ranking, and insignificantly increases the $\mathrm{H}$ type subjects' ranking in the earnings distribution.

We next compare performance in piece rate and tournament by focusing on block 2 of the Pure Piece Rate and the Mixed Tournament regimes (panels B and C in Figure 1). We use the OLS specification below for each hukou-gender type, and control for grade and school fixed effects $\delta_{s}$.

$$
Y_{i s}=\gamma_{0}+\gamma_{1} \text { salient hukou }_{i}+\gamma_{2} \text { tournament }_{i}+\gamma_{3}\left(\text { salient hukou }_{i} \cdot \text { tournament }_{i}\right)+\gamma_{4} \text { grade }_{i}+\delta_{s}+\varepsilon_{i s}
$$

The coefficient $\gamma_{1}$ (or $\gamma_{1}+\gamma_{3}$ ) measures how hukou priming affects performance in piece rate (or tournament); $\gamma_{2}$ (or $\gamma_{2}+\gamma_{3}$ ) measures the difference between tournament and piece rate in the control (or the identity treatment). Results are reported in Table 4. Column 1 shows that in the control when hukou is kept private, tournament boosts $\mathrm{H}$ boys' performance by 1.626 mazes $(p<0.05)$ relative to 
piece rate ${ }^{13}$ However, this tournament vs. piece rate difference in performance for $\mathrm{H}$ boys decreases to $0.135\left(\gamma_{2}+\gamma_{3}, p>0.10\right)$ in the identity treatment. This result, consistent with Hoff and Pandey (2011) for H caste boys, implies a reduction in H boys' competitiveness when hukou is revealed. As will be discussed later, migrant children in urban China are stereotyped to be less intelligent than their local counterparts. Influenced by this negative stereotype, $\mathrm{H}$ boys might think that they do not have to work hard to win a tournament with L boys. This leads to Result 3.

Result 3 (Tournament vs. piece rate: $\mathrm{H}$ boys). When hukou is not revealed $\mathrm{H}$ boys solve significantly more mazes in tournament than in piece rate, but not when hukou is revealed.

Column 4 of Table 4 shows that hukou priming reduces L girls' performance in piece rate by 1.382 mazes $(p<0.05)$, consistent with Result 1 . We also find that when hukou is not revealed, $\mathrm{L}$ girls solve $-0.918(p>0.10)$ less mazes in tournament than in piece rate. But when hukou is revealed, they solve 1.358 more mazes $\left(\gamma_{2}+\gamma_{3}=1.358, p<0.05\right)$ in tournament than in piece rate. This reversal of impact of priming in tournament, indicated by the significant positive tournament-hukou interaction term $(2.276, p<0.05)$, may be explained by dual discriminations against $\mathrm{L}$ girls, discussed later in this section. This leads to Result 4.

Result 4 (Tournament vs. piece rate: L girls). L girls solve significantly more mazes in tournament than in piece rate when hukou is revealed.

While results 1-4 focus on individual behavior and earnings we next ask whether the hukou system affects aggregate production efficiency at the session level. Since some sessions had fewer than six subjects due to school absence of pre-selected subjects, we use the average

\footnotetext{
${ }^{13}$ The coefficient $\gamma_{2}$ in Table 4 shows that $\mathrm{L}$ boys perform insignificantly better while both $\mathrm{H}$ and $\mathrm{L}$ girls perform insignificantly worse in tournament than in piece rate. These results are qualitatively consistent with previous findings that competition enhances performance relative to a noncompetitive environment for males but not for females (Gneezy, Niederle, and Rustichini, 2003; Gneezy and Rustichini, 2004).
} 
number of mazes solved per subject to evaluate production efficiency of sessions. Table 5 shows that per capita mazes solved are similar across the control and the identity treatments $(p>0.10)$ regardless of gender and payment regime. This suggests that the positive impact of hukou on the $\mathrm{H}$ status group and its negative impact on the L status group are counterbalanced, and the hukou system may not affect aggregate productivity. We, therefore, conclude that:

Result 5 (Aggregate production efficiency). The presence of the hukou institution does not affect the aggregate production efficiency regardless of the payment regime.

\section{Discussions of Results}

Our results indicate that individuals' behavior is distorted by the hukou institution in terms of their response to incentives. This suggests that the practice of permanently assigning households to a rural status and discriminating against them for half a century has profoundly shaped citizens' social identities, especially for the socially 'excluded' hukou groups in China.

Our results may be explained by stereotype threat, a well-established finding in social psychology and recently formalized in an economic model by Dee (2010). The stereotype threat literature in psychology shows that making social identity salient in a laboratory often makes subjects behave consistently with the stereotypes associated with that social group, and hence may activate the negative stereotypes and hurt subjects' performance in relevant tasks. Most of these studies use tasks without economic incentives (Steele and Aronson, 1995; Aronson, Quinn and Spencer, 1998; Croizet and Claire, 1998). In China rural migrants are generally stereotyped to be "uneducated, ignorant, dirty and having higher propensities to be criminals" (Wang and Zuo, 1999). Migrant children are stereotyped to be less intelligent and have low academic achievement. These negative stereotypes may be reinforced repeatedly and internalized by the 
migrant students. This self-image may be activated for migrant students following the priming of their 'inferior' hukou background in this study, and may prevent them from performing to their full potential in the assigned tasks even in the presence of economic incentives.

There are two other possible explanations for identity impact addressed by Hoff and Pandey (2006). First, the intimidation effect, i.e., knowing that they are evaluated along with their local urban counterparts may hurt migrant students' self confidence in the identity treatment. This explanation is rejected by Hoff and Pandey (2006). It is unlikely to be the primary driver of the results in this paper. Our subjects were recruited from schools where migrant students and their local urban counterparts studied and interacted on a daily basis. All the experimental sessions were conducted at subjects' regular schools during school days. Therefore, the intimidation factor, if any, is held constant across the control and the identity treatments because subjects were randomly assigned to the sessions. As a result, the findings based on the comparison across the two treatments should be net of the intimidation effect. In addition, the substantial increase in migrant girls' competitiveness in the tournament regime in the identity treatment indicates that our results are least likely to be driven by the intimidation factor.

The second hypothesis is experimenter discretion, i.e., in our case, L subjects may expect to be discriminated by the experimenters, all of who spoke Chinese Mandarin with an urban accent and hence were perceived as Beijing locals. We discount this possibility for two reasons. First, as pointed out in the discussion of experiment design, only the experimenters in a session knew the hukou status of each assigned ID. However, the maze puzzle booklets, after each block, were handed to graders outside the laboratory who did not know the hukou status of any ID number. The experimenters did not leave the laboratory throughout the session. Although the grading procedure was not announced to the subjects in advance, we conjecture that they were aware, 
particularly in block 2, that the experimenters were present in the laboratory throughout and unlikely to influence the grading process. Second, the above belief is borne out by the data as well. For instance, if our results were driven by experimenter discretion in the piece rate payment method we would observe a lower degree of performance reduction (when identity was publicly revealed) in block 2 than in block 1, since in block 2 subjects knew for certain that the experimenters were unlikely to influence the grading process. Nevertheless, we observe the opposite, i.e., the reduction in performance is actually higher in block 2. Figure 1 shows that for L boys the performance reduction from the identity treatment to the control is 0.6 in block 1 ( $p<$ 0.10 , one-side $t$ test of mean comparison) and 0.9 in block $2(p<0.10$, one-side $t$ test of mean comparison). The corresponding performance reduction is $0.5(p>0.10$, one-side Wilcoxon rank sum test) and 1.5 ( $p<0.05$, one-side Wilcoxon rank sum test) for $\mathrm{L}$ girls. This suggests that experimenter discretion is not the primary contributing factor to our results.

Recall Result 4, which shows revelation of hukou makes L girls perform significantly better in tournament than in piece rate. This finding, ascribed to an interaction effect of inferior social status and competitive environment on females' performance extends the gender gap literature that shows competition enhances performance relative to a noncompetitive environment for males but not for females (Gneezy, Niederle, and Rustichini, 2003; Gneezy and Rustichini, 2004). We conjecture that Result 4 may be explained by the twin identity of being a female and having low hukou status. Typically, migrant girls have to face dual discrimination in their lives - discrimination against rural migrants and gender discrimination. It is well accepted that in traditional Chinese society boys are preferred to girls and parents are likely to invest more in boys' education than girls'. This gender bias is more apparent in the rural areas than in the urban areas (Park and Rukumnuaykit, 2004) and in rural migrant families than in local urban 
families. In addition, rural families are more likely to have an additional child if the first child is a girl. ${ }^{14}$ Therefore, compared to other students, migrant girls are more likely to have siblings and thereby more likely to face competition in intra-household resource allocation. We presume that the combination of a competitive environment with a reminder of low status increased migrant girls' effort reversing the adverse impact of stereotype threat and ultimately leading to greater improvement in their performance in the Mixed Tournament games. ${ }^{15}$ However, more research needs to be conducted to explore this result further.

\section{Conclusion}

We conduct an experimental study to investigate the causal impact of social identity on individuals' response to economic incentives. We answer this question in the context of the role of China's household registration or hukou system in generating migrant identity. Our results indicate that making hukou identity salient adversely affects the performance of rural migrants who are lower ranked hukou holders. This adverse impact is significant and substantial for rural migrants. Making individuals' hukou status salient and public reduces the performance of rural migrant children on assigned tasks by 10 percent. The performance of individuals with a Beijing hukou improves, but insignificantly, when hukou status is made salient. Although the impact of hukou identity on aggregate efficiency is insignificant, the reduced effort of rural migrants in the identity treatment results in a drastic shift of earnings distribution to their disadvantage. This result is robust for piece rate - a widely used wage payment method in China. Moreover, this

\footnotetext{
${ }^{14}$ China's One Child Policy currently allows rural families to have an additional child if the first child is a girl, subject to government approvals and income or health constraints. Rural migrant households are also more likely to 'illegally' have additional children since it is difficult for the government to monitor the number of child births among unregistered families.

${ }^{15}$ The economic model by Dee (2010) suggests that individual performance may increase in response to stereotype threat if an increase in effort substitutes for a negative ability shock. Increase in performance by female participants exposed to gender stereotype priming is also observed in Oswald and Harvey (2000), Jamieson and Harkins (2007), Fryer, Levitt, and List (2008).
} 
larger-scale experiment avoids problems of low statistical power due to small samples observed in other studies on stereotypes.

Our results are consistent with Hoff and Pandey (2006) who find that publicly revealing young male students' caste significantly decreases the responsiveness of low castes to incentives in rural India. While they focus on male students this study shows that similar results also hold for low status female students. The evidence in this paper underlines the effect of administratively created social identity in distorting individuals' intrinsic response to incentives and thereby exacerbating inequality in the distribution of gains from economic growth in a developing country. Our study broadens the perspectives on social identities beyond race, ethnicity, religion, or caste. It shows that even in an ethnically homogeneous society like China, several-decades-long systemic policy of social exclusion can play a powerful role in creating identities and in turn influence individual behavior.

As suggested by Akerlof and Kranton's (2000) identity model of social exclusion, the negative impact of social exclusion is unlikely to disappear unless citizens are fully integrated into a community. Future research should, thus, study the long term impact of identity on educational attainment and labor market outcomes of low status individuals. This strand of research will provide critical insights for designing redistributive and inclusive policies that aim to achieve more cohesive communities. 


\section{Acknowledgements}

We are grateful to Karla Hoff for sharing her insights and experiment materials. We would also

like to thank Rachel Croson, Catherine Eckel, Albert Park, Ragan Petrie, Marco Castillo and seminar participants at the UT-Dallas behavioral/experimental reading group, the International ESA meetings (Caltech, 2008), the Chinese Economist Society annual meeting (Nanning, China, 2009), George Mason University, Florida State University, East Carolina University, the Indian Statistical Institute (Delhi) and the Delhi School of Economics for their helpful comments. Li acknowledges the financial support from the National Science Foundation through grant no. SES 0720936. Any remaining errors are our own.

\section{References}

Akerlof, G.A. and Kranton, R.E. (2000). 'Economics and Identity', Quarterly Journal of Economics, vol. 115(3), pp. 715-753.

Aronson, J., Quinn D. and Spencer S. (1998). 'Stereotype Threat and the Academic Underperformance of Minorities and Women', in (J. K. Swim and C. Stangor, eds.), Prejudice: The Target's Perspective. New York: Academic Press.

Bargh, J.A. (2006). 'What Have We Been Priming All These Years? On the Development, Mechanisms, and Ecology of Nonconscious Social Behavior', European Journal of Social Psychology, vol. 36(2), pp. 147-168.

Beijing Municipal Bureau of Statistic, (2005). Beijing, China: China Statistical Press.

Benabou, R. and Tirole, J. (2007). 'Identity, Dignity and Taboos: Beliefs as Assets', CEPR Discussion Paper No. DP6123.

Benjamin, D.J., Choi, J.J. and Strickland, A.J. (2010). 'Social Identity and Preferences', American Economic Review, vol. 100(4), pp. 1913-1928.

Benjamin, D.J., Choi, J.J. and Geoffrey, F. (2010). 'Religious Identity and Economic Behavior', NBER Working Paper 15925, November 2010.

Chan, K.W. (1996). 'Post-Mao China: A Two-Class Urban Society in the Making', International Journal of Urban and Regional Research, vol. 20(1), pp. 134-150.

Chan, K. W. and Zhang, L. (1999). 'The Hukou System and Rural-Urban Migration in China: Processes and Changes', The China Quarterly, vol. 160, pp. 818-855.

Charness, G., Cobo-Reyes, R. and Jiménez, N. (2011). 'Efficiency, Team building, and Identity in a Public-goods Game', UCSB working paper.

Charness, G., Rigotti, L. and Rustichini, A. (2007). 'Individual behavior and group membership', 
American Economic Review, vol. 97, pp. 1340 - 1352.

Chen, A. (2002). 'Urbanization and Disparities in China: Challenges of Growth and Development', China Economic Review, vol. 13(4), pp. 407-411.

Chen, R. and Chen, Y. (Forthcoming). 'The Potential of Social Identity for Equilibrium Selection', American Economic Review.

Chen, Y. and Li, S. (2009). 'Group Identity and Social Preferences', American Economic Review, vol. 99(1), pp. 431-457.

Cheng, T. and Selden, M. (1994). 'The Origins and Social Consequences of China's Hukou System', The China Quarterly, vol. 139, pp. 644-668.

National Bureau of Statistics of China. 1994-2003. China Statistical Yearbook. Beijing, China: China Statistical Press.

China's Social Security and Its Policy (2004). http://www.gov.cn/english/official/200507/28/content_18024.htm.

Croizet, J. and Claire, T. (1998). 'Extending the Concept of Stereotype Threat to Social Class: The Intellectual Underperformance of Students from Low Socioeconomic Backgrounds', Personality and Social Psychology Bulletin, vol. 24(6), pp. 588-594.

Datt, G, and Ravallion, M. (2002). 'Is India's Economic Growth Leaving the Poor Behind?', Journal of Economic Perspectives, vol. 16(3), pp. 89-108.

Deaton, A. and Dreze, J. (2002). 'Poverty and Inequality in India: A Re-examination', Economic and Political Weekly, vol. 37, pp. 3729-3748.

Dee, T. (2010). 'Stereotype Threat and the Student-Athlete', NBER Working Paper No. 14705.

Eckel, C.C. and Grossman, P.J. (2005). 'Managing Diversity by Creating Team Identity', Journal of Economic Behavior \& Organization, vol. 58 (3), pp. 371-392.

Fang, H. and Loury G. (2005). 'DDysfunctional Identities' Can Be Rational', American Economic Review, vol. 95(2), pp. 104-111.

Gneezy, U., Niederle, M. and Rustichini, A. (2003). 'Performance in Competitive Environments: Gender Differences', Quarterly Journal of Economics, vol. 118(3), pp. 1049-1074.

Gneezy, U. and Rustichini, A. (2004). 'Gender and Competition at a Young Age', American Economic Review, vol. 94(2), pp. 377-381.

Goette, L., Huffman, D. and Meier, S. (2006). 'The Impact of Group Membership on Cooperation and Norm Enforcement: Evidence Using Random Assignment to Real Social Groups', American Economic Review, vol. 96 (2), pp. 212-216.

Harrison, G.W., and List, J.A. (2004). 'Field Experiments', Journal of Economic Literature, vol. 42(4), pp. 1009-1055.

Hoff, K. and Pandey, P. (2005). 'Opportunity is not Everything', Economics of Transition, vol. 13(3), pp. 445-472.

Hoff, K. and Pandey, P. (2006). 'Discrimination, Social Identity, and Durable Inequalities', American Economic Review Papers \& Proceedings, vol. 96(2), pp. 206-211.

Hoff, K. and Stiglitz, J. (2010). 'Equilibrium Fictions: A Cognitive Approach to Societal Rigidity', American Economic Review Papers \& Proceedings, vol. 100(2), pp. 141-146.

Horst, U., Kirman, A. and Teschl, M. (2006). 'Changing Identity: The Emergence of Social Groups', Working Paper, University of British Columbia. 
Kanbur, R. and Zhang, X. (1999). 'Which Regional Inequality? The Evolution of Rural-Urban and Inland-Coastal Inequality in China from 1983 to 1995', Journal of Comparative Economics, vol. 27(4), pp. 686-701.

Lin, J.Y, Cai, F., and Li, Z. (1996). The China Miracle: Development Strategy and Economic Reform, Hong Kong, China: The Chinese University Press.

Liu, Z. (2005). 'Institution and Inequality: The Hukou System in China', Journal of Comparative Economics, vol. 33(1), pp. 133-157.

Lu, Z. and Song S. (2006). 'Rural-Urban Migration and Wage Determination: The Case of Tianjin, China', China Economic Review, vol. 17(3), pp. 337-345.

Niederle, M. and Vesterlund, L. (2007). 'Do Women Shy Away from Competition? Do Men Compete Too Much?' Quarterly Journal of Economics, vol. 122(3), pp. 1067-1101.

Park, A. and Rukumnuaykit, P. (2004). 'Eat Drink Man Woman: Testing for Gender Bias in China Using Individual Nutrient Intake Data', Working paper, Oxford University.

Persson, T. and Tabellini, G. (1994). 'Is Inequality Harmful for Growth?', The American Economic Review, vol. 84(3), pp. 600-621.

Ravallion, M. (1997). 'Can High-Inequality Developing Countries Escape Absolute Poverty?', Economics Letters, vol. 56(1), pp. 51-57.

Ravallion, M. and Chen, S. (2007). 'China's (uneven) Progress against Poverty', Journal of Development Economics, vol. 82(1), pp. 1-42.

Shayo, M. (2005). 'Nation, Class and Redistribution: Applying Social Identity Research to Political Economy', Working Paper, Princeton University.

Shih, M., Pittinsky, T.L. and Ambady, N. (1999). 'Stereotype Susceptibility: Identity Salience and Shifts in Quantitative Performance', Psychological Science, vol. 10(1), pp. 81-84.

Solinger, D.J. (1999). Contesting Citizenship: Peasant Migrants, the State and the Logic of the Market in Urban China. Berkeley, CA: University of California Press.

Steele, C.M. and Aronson, J. (1995). 'Stereotype Threat and the Intellectual Test Performance of African-Americans', Journal of Personality and Social Psychology, vol. 69(5), pp. 797-811.

National Bureau of Statistics of China. (2002). Tabulation on the 2000 Population Census of the People's Republic of China, Beijing, China: China Statistical Press.

Whalley, J. and Zhang, S. (2007). 'A Numerical Simulation Analysis of (Hukou) Labor Mobility Restrictions in China', Journal of Development Economics, vol. 83(2), pp. 392-410.

Xinhua News Agency. 2002. http://www.china.org.cn/english/China/36594.htm.

Xinhuanet. 2009. http://news.xinhuanet.com/politics/2009-02/05/content_10769408.htm.

Yao, S., Zhang, Z. and Hanmer, L. (2004). 'Growing Inequality and Poverty in China', China Economic Review, vol. 15(2), pp. 145- 163. 


\section{Table 1: Experimental Design}

\begin{tabular}{l|l|l|l|lc}
\hline \multirow{2}{*}{ Treatments } & \multirow{2}{*}{ Primed hukou? } & \multicolumn{2}{l|}{ Reward per maze } & \multicolumn{2}{l}{ Number of sessions } \\
\cline { 3 - 6 } & & Block 1 & Block 2 & Male & Female \\
\hline $\begin{array}{l}\text { 1. Pure Piece Rate control treatment } \\
\text { 2. Mixed Tournament control }\end{array}$ & No & $¥ 1$ & $¥ 1$ & 9 & 6 \\
treatment & No & $¥ 1$ & $¥ 6$; winner takes all & 9 & 5 \\
$\begin{array}{l}\text { 3. Pure Piece Rate identity treatment } \\
\begin{array}{l}\text { 4. Mixed Tournament identity } \\
\text { treatment }\end{array}\end{array}$ & Yes & $¥ 1$ & $¥ 1$ & 15 & 7 \\
\hline
\end{tabular}

Note: The experiment consists of 418 subjects.

Table 2: Summary Statistics

\begin{tabular}{|c|c|c|c|c|c|c|c|}
\hline \multirow{2}{*}{ Variables } & \multicolumn{3}{|c|}{ Control Treatment } & \multicolumn{3}{|c|}{ Identity Treatment } & \multirow{2}{*}{ Two-side $p$ value ${ }^{a}$} \\
\hline & Mean & Std. Dev. & Obs. & Mean & Std. Dev. & Obs. & \\
\hline Grade & 4.28 & 1.04 & 168 & 4.37 & 1.10 & 250 & 0.41 \\
\hline Age (years) & 9.84 & 1.32 & 168 & 9.80 & 1.27 & 250 & 0.76 \\
\hline Mazes (block 1) & 6.19 & 2.44 & 168 & 6.10 & 2.27 & 250 & 0.71 \\
\hline Mazes (block 2) & 8.46 & 2.87 & 168 & 8.56 & 2.84 & 250 & 0.74 \\
\hline Total earnings ${ }^{b}$ & 19.70 & 21.26 & 168 & 19.60 & 20.77 & 250 & 0.96 \\
\hline Years of local residence ${ }^{c}$ & 5.78 & 3.40 & 63 & 5.60 & 2.85 & 91 & 0.73 \\
\hline \multicolumn{8}{|l|}{ Father's education } \\
\hline High school & 0.42 & 0.50 & 156 & 0.38 & 0.49 & 247 & 0.35 \\
\hline College/Graduate degree & 0.25 & 0.43 & 156 & 0.25 & 0.43 & 247 & 0.98 \\
\hline \multicolumn{8}{|l|}{ Mother's education } \\
\hline High school & 0.40 & 0.49 & 155 & 0.35 & 0.48 & 246 & 0.27 \\
\hline College/Graduate degree & 0.23 & 0.42 & 155 & 0.24 & 0.43 & 246 & 0.68 \\
\hline $\begin{array}{l}\text { Fraction of subjects who } \\
\text { played similar/same } \\
\text { games before }\end{array}$ & 0.73 & 0.45 & 168 & 0.68 & 0.47 & 250 & 0.28 \\
\hline Number of others known & 1.39 & 1.47 & 165 & 1.36 & 1.28 & 250 & 0.80 \\
\hline
\end{tabular}

Notes:

a. The two-side $p$ values are based on the $t$ test of means or proportions.

b. Total experimental earnings include the $¥ 3$ participation fee.

c. Years of local residence are for those who were not born in Beijing. 
Table 3: Impact of Hukou Identity on Performance and Earnings

\begin{tabular}{|c|c|c|c|c|}
\hline & (1) & (2) & (3) & (4) \\
\hline Empirical model & OLS & OLS & OLS & $\begin{array}{l}\text { Ordered } \\
\text { probit }\end{array}$ \\
\hline Dep. var. & Performance & Performance & $\begin{array}{l}\text { Earning } \\
\text { percentile }\end{array}$ & $\begin{array}{l}\text { Earnings } \\
\text { distribution } \\
\text { category }\end{array}$ \\
\hline Treatment & $\begin{array}{l}\text { Piece rate } \\
\text { blocks }\end{array}$ & $\begin{array}{l}\text { Tournament } \\
\text { block }\end{array}$ & $\begin{array}{l}\text { Pure Piece } \\
\text { Rate } \\
\text { regime }\end{array}$ & $\begin{array}{l}\text { Pure Piece } \\
\text { Rate } \\
\text { Regime } \\
\end{array}$ \\
\hline $\begin{array}{l}\text { salient hukou } \\
\text { (identity) }\end{array}$ & $\begin{array}{l}0.300 \\
(0.360)\end{array}$ & $\begin{array}{l}-0.297 \\
(0.556)\end{array}$ & $\begin{array}{l}7.458 \\
(5.103)\end{array}$ & $\begin{array}{l}0.175 \\
(0.216)\end{array}$ \\
\hline $\mathrm{L}$ & $\begin{array}{l}0.386 \\
(0.361)\end{array}$ & $\begin{array}{l}-0.673 \\
(0.561)\end{array}$ & $\begin{array}{l}9.185 \\
(5.596)\end{array}$ & $\begin{array}{l}0.279 \\
(0.234)\end{array}$ \\
\hline $\mathrm{L} \times$ salient hukou & $\begin{array}{l}-1.072 * * \\
(0.457)\end{array}$ & $\begin{array}{l}0.421 \\
(0.726)\end{array}$ & $\begin{array}{l}-19.198 * * * \\
(7.219)\end{array}$ & $\begin{array}{l}-0.701 * * \\
(0.304)\end{array}$ \\
\hline female & $\begin{array}{l}-1.046^{* * * *} \\
(0.251)\end{array}$ & $\begin{array}{l}-1.313 * * * \\
(0.395)\end{array}$ & $\begin{array}{l}-13.935^{* * * *} \\
(4.023)\end{array}$ & $\begin{array}{l}-0.498 * * * \\
(0.170)\end{array}$ \\
\hline grade & $\begin{array}{l}0.797 * * * \\
(0.105)\end{array}$ & $\begin{array}{l}1.112 * * * \\
(0.165)\end{array}$ & $\begin{array}{l}9.653 * * * \\
(1.705)\end{array}$ & $\begin{array}{l}0.347 * * * \\
(0.074)\end{array}$ \\
\hline block 2 & $\begin{array}{l}2.283 * * * \\
(0.155)\end{array}$ & & & \\
\hline Constant & $\begin{array}{l}3.139 * * * \\
(0.559)\end{array}$ & $\begin{array}{l}4.896 * * * \\
(0.916)\end{array}$ & $\begin{array}{l}11.575 \\
(9.443)\end{array}$ & \\
\hline Observations & 635 & 201 & 217 & 217 \\
\hline Adjusted $\mathrm{R}^{2}$ & 0.304 & 0.264 & 0.184 & 0.067 \\
\hline
\end{tabular}

Notes: The analysis in column (1) is based on the Pure Piece Rate regime and block 1 of the Mixed Tournament regime. Standard errors in the parentheses are clustered at the individual level when multiple observations come from the same individual. Analysis in column (2) is based on block 2 of the mixed tournament regime. Consistent with Figure 3, the dependent variable "earnings distribution category" in column (4) takes values of 1, 2, 3 and 4 if one's earning is below the $25^{\text {th }}$ percentile, between the $25^{\text {th }}$ and $50^{\text {th }}$, between the $50^{\text {th }}$ and $75^{\text {th }}$, and above the $75^{\text {th }}$ percentile of the earnings distribution. School fixed effects are included in all the analyses. * significant at 10 percent level, ** significant at 5 percent level, $* * *$ significant at 1 percent level. 
Table 4: Performance in Piece Rate and Tournament (OLS)

\begin{tabular}{l|llll}
\hline & $(\mathbf{1})$ & $(\mathbf{2})$ & $\mathbf{( 3 )}$ & $\mathbf{( 4 )}$ \\
\cline { 2 - 5 } & $\mathbf{H}$ boys & H girls & L boys & L girls \\
\hline salient hukou $\left(\gamma_{1}\right)$ & 0.632 & 0.810 & -0.904 & $-1.382^{* *}$ \\
$\quad$ identity) & $(0.650)$ & $(0.936)$ & $(0.608)$ & $(0.629)$ \\
tournament $\left(\gamma_{2}\right)$ & $1.626^{* *}$ & 0.250 & -0.942 & -0.918 \\
& $(0.740)$ & $(1.008)$ & $(0.672)$ & $(0.681)$ \\
tournament $\times$ salient hukou $\left(\gamma_{3}\right)$ & -1.491 & -0.483 & 1.006 & $2.276^{* *}$ \\
& $(0.929)$ & $(1.385)$ & $(0.849)$ & $(0.932)$ \\
grade & $0.835^{* * *}$ & $1.045^{* * *}$ & $1.309^{* * *}$ & $0.885^{* * *}$ \\
& $(0.220)$ & $(0.334)$ & $(0.198)$ & $(0.220)$ \\
Constant & $5.547^{* * *}$ & 2.134 & $3.316^{* * *}$ & $4.941^{* * *}$ \\
& $(1.199)$ & $(1.749)$ & $(1.043)$ & $(1.079)$ \\
Observations & 139 & 70 & 139 & 70 \\
Adjusted $\mathrm{R}^{2}$ & 0.134 & 0.065 & 0.264 & 0.240 \\
\hline P values & & & & \\
$\gamma_{1+} \gamma_{3}=0$ & 0.20 & 0.75 & 0.87 & 0.20 \\
$\gamma_{2} \gamma_{3}=0$ & 0.81 & 0.81 & 0.90 & 0.04 \\
\hline
\end{tabular}

Notes: The analysis pools data in block 2 of the Pure Piece Rate regime and the Mixed tournament regime. School fixed effects are included.

* significant at 10 percent level, ** significant at 5 percent level, *** significant at 1 percent level.

Table 5: Impact of Hukou Identity on Economic Efficiency

\begin{tabular}{llll|lll|lll}
\hline \multirow{2}{*}{ Gender } & \multicolumn{3}{l|}{ Block 1 (all piece rate) } & \multicolumn{3}{l|}{ Block 2 piece rate } & \multicolumn{3}{l}{ Block 2 tournament } \\
\cline { 2 - 9 } & control & identity & p value & control & identity & p value & control & identity & p value \\
\hline Boys & 6.6 & 6.41 & 0.53 & 8.85 & 8.87 & 0.97 & 9.35 & 9.03 & 0.53 \\
Girls & 5.54 & 5.39 & 0.69 & 7.63 & 7.27 & 0.50 & 7.27 & 8.12 & 0.22 \\
\hline
\end{tabular}

Notes: Two-side p-values are based on the $\mathrm{t}$ test of means for boys, and the Wilcoxon rank sum test for girls. Data in the first block of the Pure Piece Rate regime and the Mixed Tournament regime are pooled because of the identical design. 
Figure 1: Performance in Solving Mazes
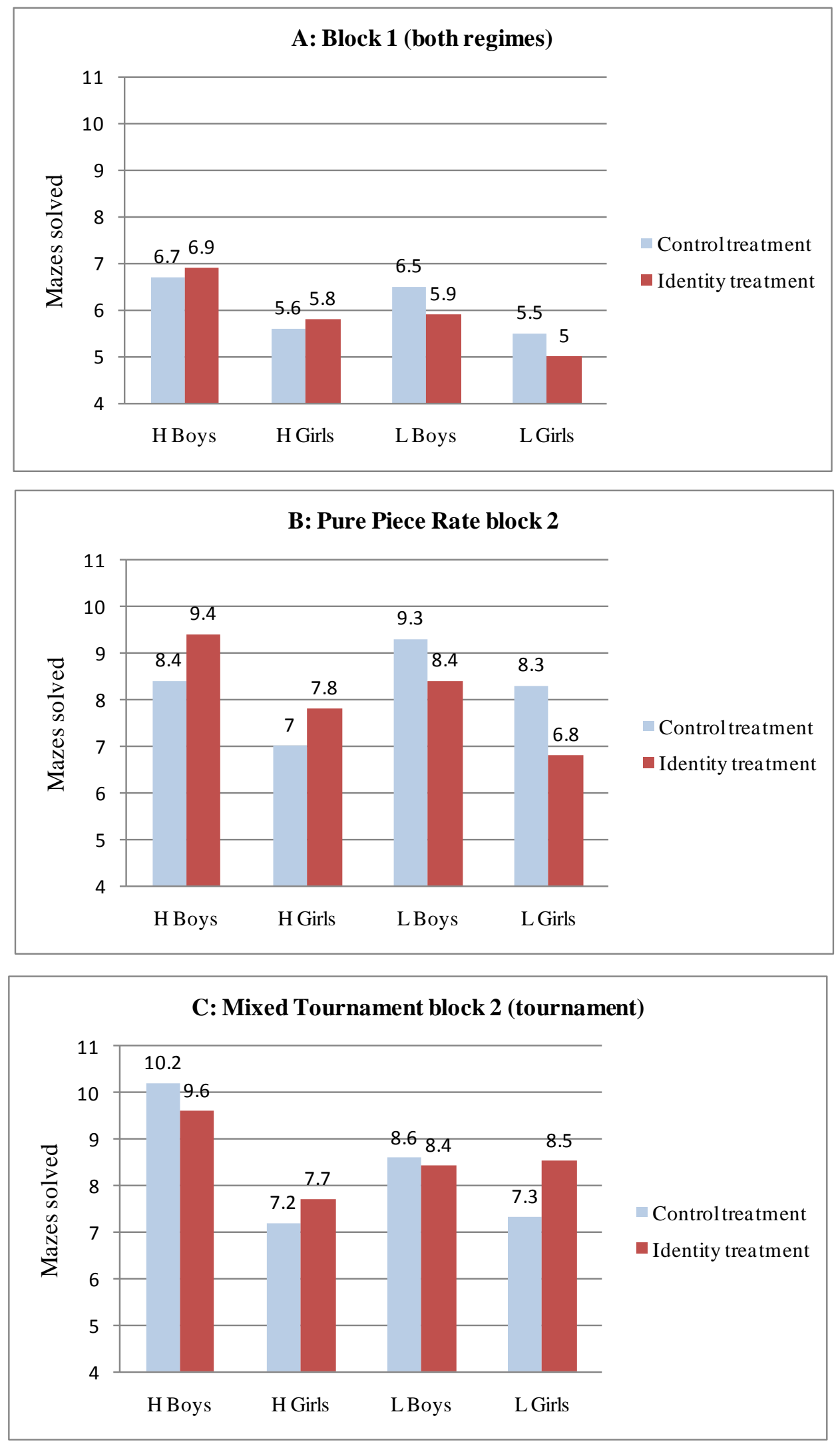
Figure 2: Experimental Earnings in the Pure Piece Rate Regime
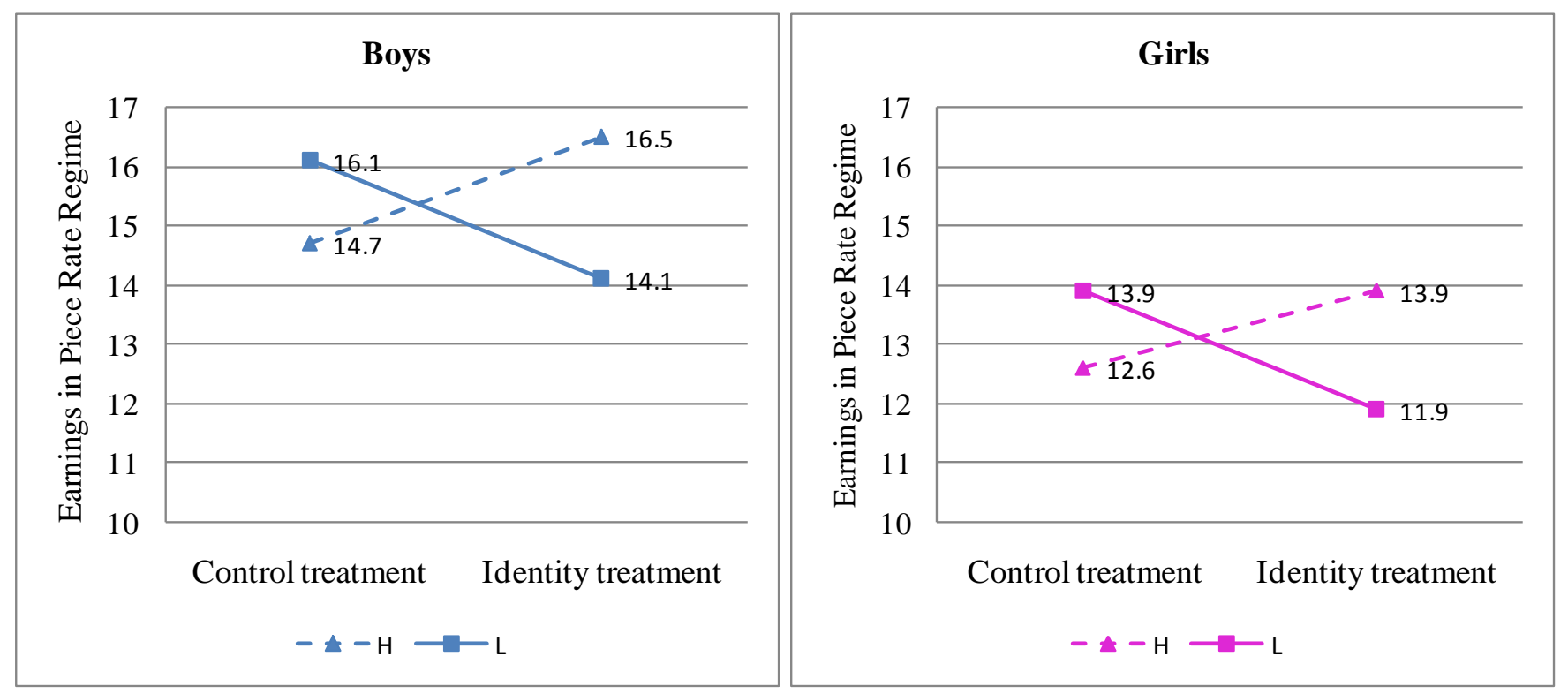
Figure 3: Earnings Distribution under the Pure Piece Rate Regime

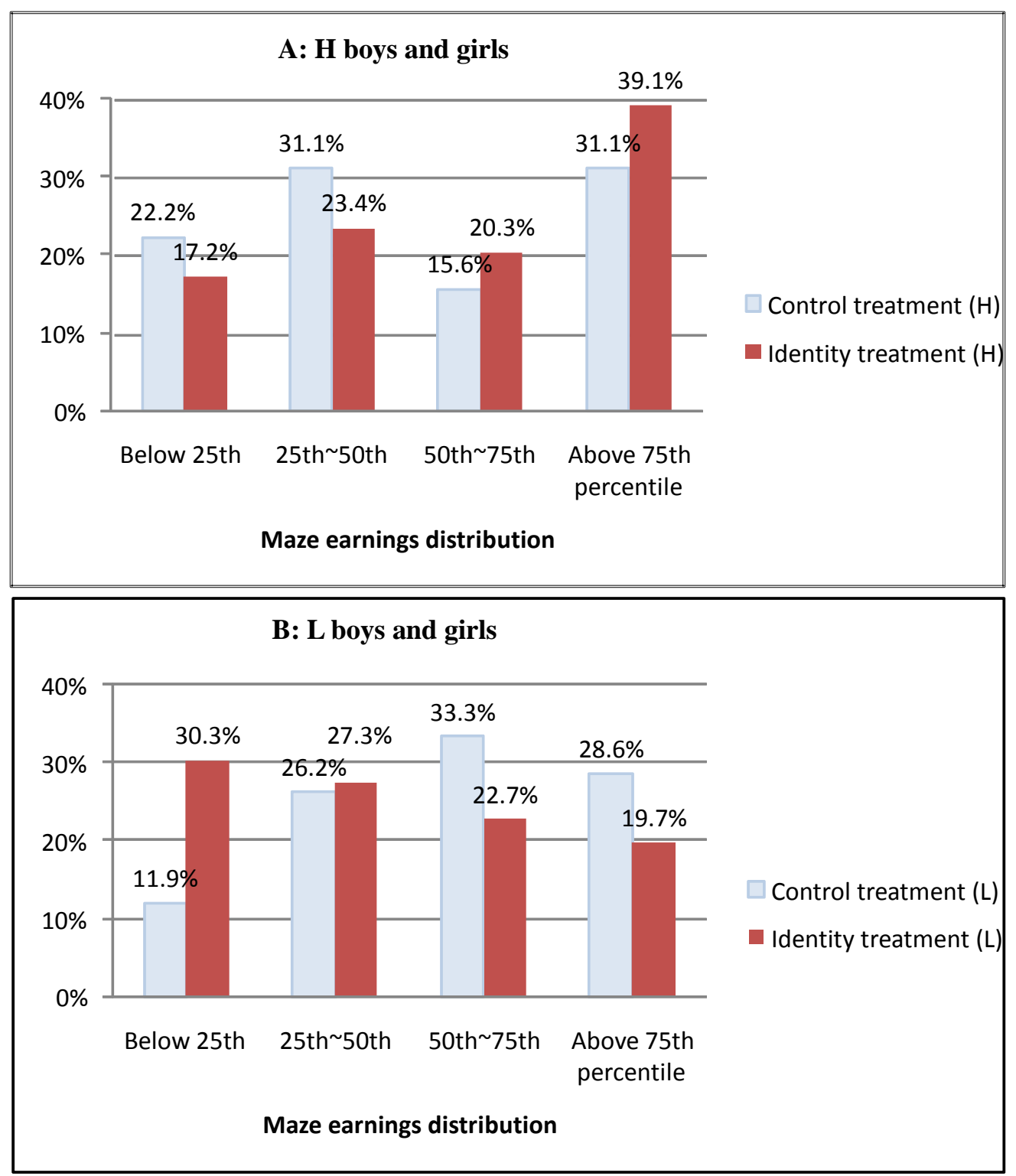




\section{NOT FOR PUBLICATION}

\section{Appendix A. A Sample Maze Game}
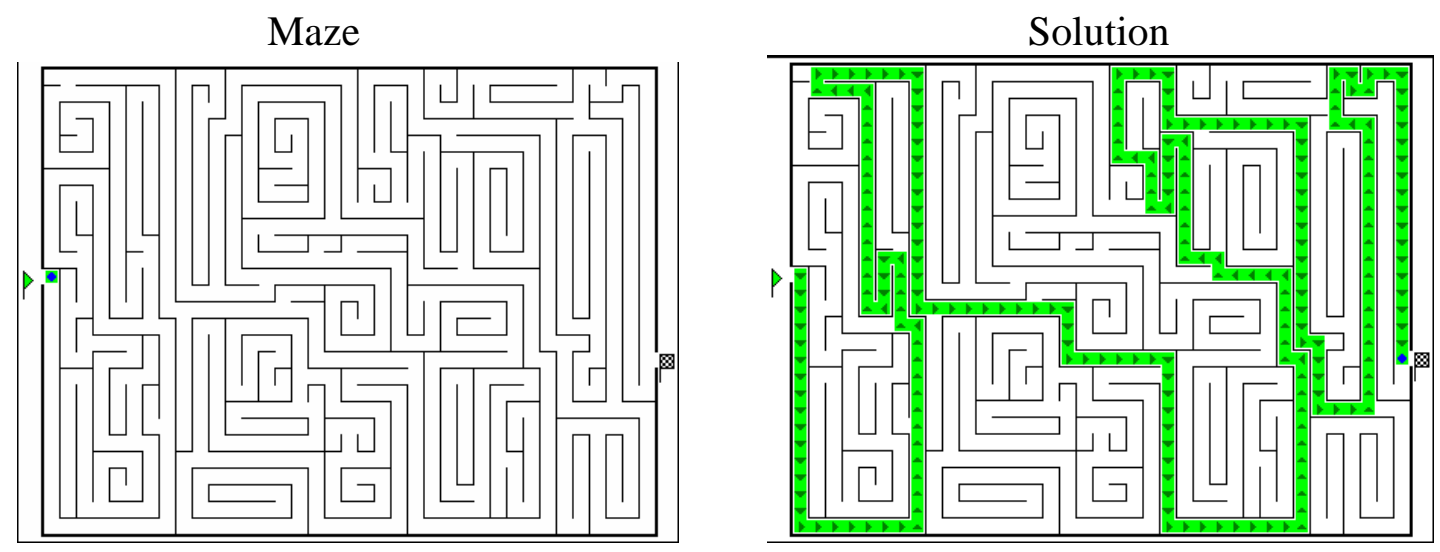

\section{Appendix B. Experimental Instruction}

The instruction was given in Chinese. The English translation is presented below with the instructions for experimenters included in the parentheses in italics.

\section{Piece rate without hukou primed}

1. Welcome! Each of you will be compensated with 3 yuan for your participation. Please find 3 yuan in the envelope on your desk. It is yours to keep.

2. In addition, you may earn more money in the games. The average earnings will be about 12 to 18 yuan. You will be paid in cash in private at the end of the games. You are under no obligation to let others know how much you earn. You will participate in two rounds of maze solving games. The entire games will last about half an hour. Please do not talk to each other during the experiment. Please raise your hand if you had any questions.

3. First, we will show you what the game looks like and how to solve it. (Experimenter reveals the first sample maze and explains while drawing on the poster.) On the left hand side of the maze, it is the entrance indicated by a triangle flag. On the right hand side, it is the exit indicated by a square flag. The black lines are walls. Your task is to find a path from the entrance to the exit without crossing the walls. You may erase or cross out if you make any mistakes.

4. Let's look at the second example. It is similar to what you will need to solve in the games. (Experimenter reveals the second example and illustrates how to solve it).

5. Now you will be given another maze for practice. Everyone will have 5 minutes to do so. If you have any questions, please raise your hand and we will come to you.

6. Next, we will start the first round of the games. Please find the booklet that says 'Round 1' on the cover. Please don't open the booklet until you are told to do so. There is one maze on each page, and in total 15 games. Everyone will be given 15 minutes to solve as many games as you can. You don't need to solve those games in order. You may skip any game as you like.

7. Now we will explain the rewards. For this round, you will get 1 yuan for each maze you solve correctly. So if you solve one, you will get one yuan. If you solve two, you will get two yuan ...

(Experimenter reveals the following table on the blackboard and goes through this hypothetical example to make 
sure every subject follows the calculation of rewards. Experimenter asks subject no. 1, 'suppose Qiang solve 4 mazes, how much he will earn?' Then experimenter asks subject no. 2 how much Gang will earn... Hypothetical female names are used in the table if it is female session.)

\begin{tabular}{lll}
\hline Name & Number of mazes solved & Rewards \\
\hline Qiang & 4 \\
Gang & 7 \\
Peng & 9 \\
Wei & 12 & \\
Hao & 14 \\
Dong & 5 & \\
\hline
\end{tabular}

8. Recall you will have 15 minutes to solve as many mazes as you can. When 5 minutes remain we will let you know. When time is up, please put down the pencil immediately and close the booklet. Please open the booklet now. You may start. (Experimenter collects the booklet when round 1 is over.)

9. Next we will explain the games in round 2. Please find the booklet that says 'Round 2' on the cover. Please don't open it until you are told to do so. The booklet contains another 15 games with the same difficulty level.

10-PieceRate. The rules and rewards in round 2 are exactly the same as that in round 1. Let's review the reward calculation again. (Experimenter reviews the reward table above without checking with individual subjects.)

11. Again you will have 15 minutes to solve as many mazes as you can. We will let you know when 5 minutes are left. Please open the booklet now. You may start. (Experimenter collects the booklet when round 2 is over.)

12. Please find the booklet that says 'Survey' on the cover. While we are grading your games and computing your payoffs please complete the survey. Please try to answer as many questions as you can. We are not going to share individual answers with anyone else including your teachers.

13. You will now be paid in private. Remember you don't have to tell others how much you earned. Thank you for your participation in our study!

\section{Tournament without hukou primed}

(Replace step 10-PieceRate above with step 10-Tournament below. Keep other steps the same as in Piece Rate.) 10-Tournament. Please note that the rules now are different from round 1 . In this round, you will compete with each other. Only the winner(s) will get rewards. The winner(s) is/are the person(s) who solve(s) the greatest number of mazes. The reward for the winner(s) is 6 yuan each game. So if he solves one maze, he will get 6 yuan. If he solves two mazes, he will get 12 yuan. If he solves three mazes, he will get 18 yuan... If it's a tie, all the winners will be compensated. Each of them will get 6 yuan per game. Let's go over one example.

\begin{tabular}{llll}
\hline Name & Number of mazes solved & Winner & Rewards \\
\hline Qiang & 4 & & \\
Gang & 7 & & \\
Peng & 9 & & \\
Wei & 12 & \\
Hao & 14 & \\
Dong & 5 & & \\
\hline
\end{tabular}

(Experimenter adds one more column 'winner' in the reward calculation table. Experimenter checks with each subject, e.g., 'Is Qiang the winner? How much does he earn in this case?')

$\underline{\text { III. Piece rate with hukou primed }}$

(Same as I. except that Step 0 is added.) 
0. Welcome! Each of you will be compensated with 3 yuan for your participation. Please find 3 yuan in the envelope on your desk. It is yours to keep. Now please find the booklet that says 'Survey 1' on the cover. Please try to answer as many questions as you can. We will keep your answers confidential and will not share them with anyone else including your teachers. (After everyone completes the survey, experimenter goes to each student, and verifies in public their names, month and date of birth, and hukou information. Students nod and say yes if information is correct.)

IV. Mixed Tournament with Hukou Announced

The same as Mixed Tournament except that Step 0 is added.

V.A. Mixed Tournament with Hukou Announced, and H Only

The same as Mixed Tournament except that Step 0 is added. Note there are 6 Beijing urban students $(\mathrm{H})$ in this session.

V.B. Mixed Tournament with Hukou Announced, and M Only

The same as Mixed Tournament except that Step 0 is added. Note there are 6 Non-Beijing urban students (M) in this session.

V.C. Mixed Tournament with Hukou Announced, and L Only

The same as Mixed Tournament except that Step 0 is added. Note there are 6 Non-Beijing rural students (L) in this session. 


\section{Appendix C. Pre-experimental Survey (used in the HL treatment)}

1. Place of birth: ___ province ___ city ___ street/village

2. If you were not born in Beijing, when did you move to Beijing? year

3. The location of your hukou: province city street/village

$\square$ Check here if you don't know the answer.

5. Which dialect do you speak with your parents at home?

a) Beijing dialect, b) Other, please specify

6. Do you consider yourself as Beijing local?

a) Yes, b) Somewhat, c) No, d) Don't know

7. Do your classmates consider you as Beijing local?

a) Yes, b) Somewhat, c) No, d) Don't know

8. Do your teachers consider you as Beijing local?

a) Yes, b) Maybe, c) No, d) Don't know

9. Were you charged 40 yuan rural guest student fee or 80 yuan local student fee at the beginning of this semester?

a) 40 yuan (rural guest student fee), b) 80 yuan (local student fee), c) other

10. Where do the students come from in your class?

a) All from Beijing, b) Most from Beijing, and some from elsewhere,

c) Some from Beijing, and most from elsewhere, d) Don't know

11. Compare Beijing local students and those from non-Beijing rural areas, what are your opinions regarding the following questions?

i) Who generally study harder?

a) Beijing local students, b) Students from non-Beijing rural areas,

c) They study equally hard.

ii) Who are more active participating in classes, e.g., ask and answer questions?

a) Beijing local students, b) Students from non-Beijing rural areas,

c) They are equally active in class participation.

iii) Who are more active participating in extracurricular activities?

a) Beijing local students, b) Students from non-Beijing rural areas,

c) They are equally active in those activities.

iv) Who are thriftier with money?

a) Beijing local students, b) Students from non-Beijing rural areas,

c) They are equally so. 


\section{Appendix D. Post-experimental Survey ${ }^{16}$}

1. Place of birth: ___ province ___ city____ street/village

2. If you were not born in Beijing, when did you move to Beijing? year

3. The location of your hukou: province city street/village

$\square$ Check here if you don't know the answer.

4. Your father's employer:

a) Government, including military, b) State owned company, c) Privately owned company,

d) Foreign invested enterprises, e) Self-employed, f) Others, please specify:

5. Your father's highest level of education achieved:

a) Elementary school, b) Middle school, c) High school, d) College, e) University, f) Graduate school 6. Your mother's employer:

a) Government, including military, b) State owned company, c) Privately owned company,

d) Foreign invested enterprises, e) Self-employed, f) Others, please specify:

7. Your mother's highest level of education achieved:

a) Elementary school, b) Middle school, c) High school, d) College, e) University, f) Graduate school

8. Your average ranking in your class is:

a) Top $25 \%$, b) $25 \%-50 \%$, c) $50 \%-75 \%$, d) $75 \%-100 \%$, e) don't know for sure

9. Do you like living in the current residential area?

a) Like it very much, b) Like, c) neutral, d) Dislike, e) Dislike it very much

10. Where will you want to live when growing up?

a) Beijing, b) Your hometown, please specify

c) Other cities in China, please specify , d) Foreign country, please specify

11. What is your ideal job when growing up?

12. How much pocket money do your parents give to you per week? (Please exclude the expense on meals and transportation)

a) Less than 3.5 yuan, b) 3.5-7 yuan, c) 7-10.5 yuan, d) 10.5-14 yuan, e) more than 14 yuan

13. Have you ever played this kind of maze game before?

a) No, b) Played similar games before, c) Played exactly the same games before

14. How hard did you think these maze games were?

a) Very hard, b) Hard, c) Neutral, d) Easy, e) Very easy

15. How many other students in this session do you know by name?

a) 0, b)1, c) 2 , d) 3, e) 4, f) 5

\footnotetext{
${ }^{16}$ For the treatment sessions, the first three questions were included in the pre-experiment survey.
} 


\section{Appendix E}

Figure A1: Hukou Identity and Earnings under the Pure Piece Rate Regime
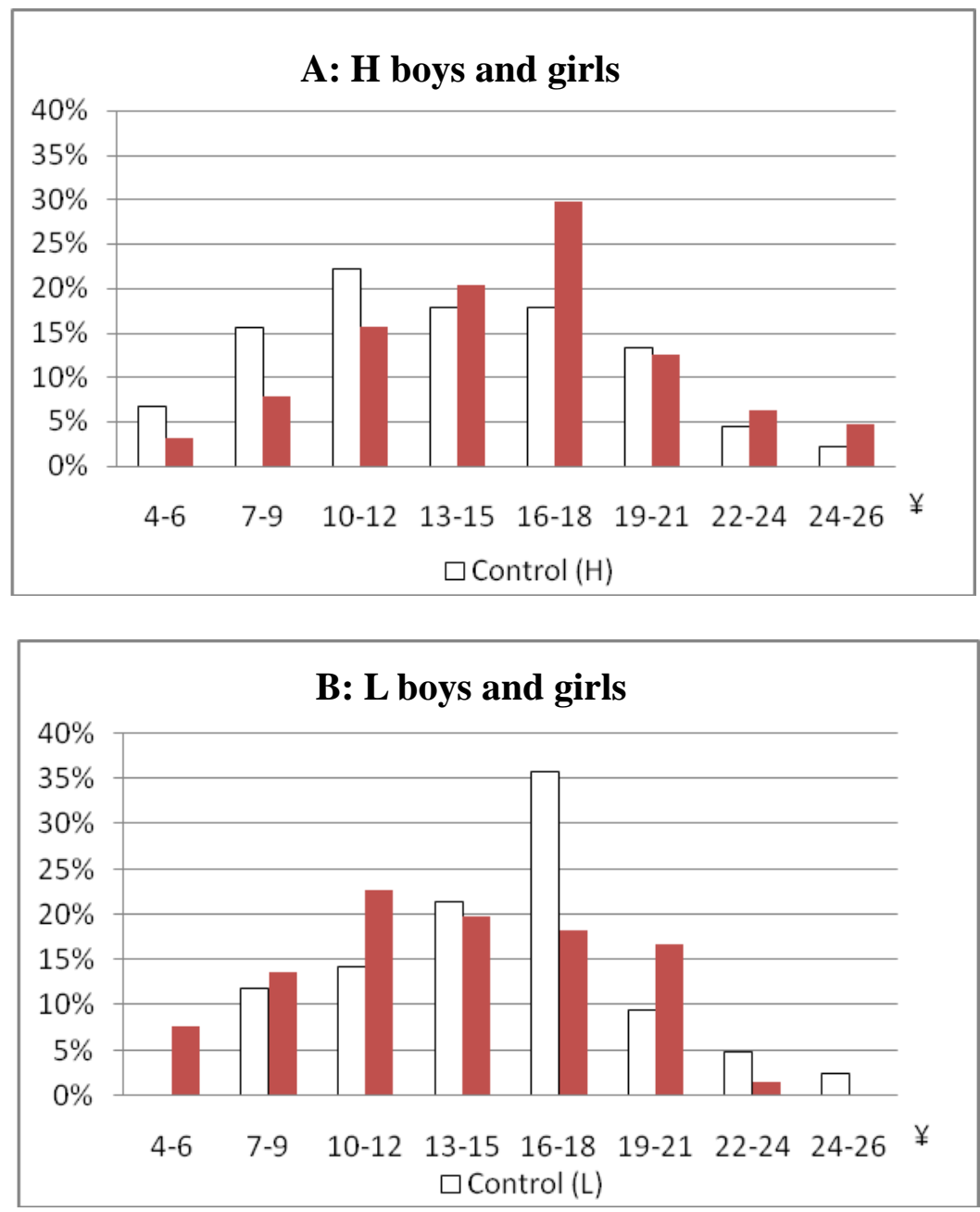